\title{
Recent trends in groundwater levels in a highly seasonal hydrological system: the Ganges-Brahmaputra-Meghna Delta
}

\author{
M. Shamsudduha ${ }^{1}$, R. E. Chandler ${ }^{2}$, R. G. Taylor ${ }^{1}$, and K. M. Ahmed ${ }^{3}$ \\ ${ }^{1}$ Department of Geography, University College London, London, UK \\ ${ }^{2}$ Department of Statistical Science, University College London, London, UK \\ ${ }^{3}$ Department of Geology, University of Dhaka, Dhaka, Bangladesh
}

Received: 20 April 2009 - Published in Hydrol. Earth Syst. Sci. Discuss.: 8 June 2009

Revised: 21 October 2009 - Accepted: 23 November 2009 - Published: 10 December 2009

\begin{abstract}
Groundwater levels in shallow aquifers underlying Asian mega-deltas are characterized by strong seasonal variations associated with monsoon rainfall. To resolve trend and seasonal components in weekly groundwater levels in the Ganges-Brahmaputra-Meghna (GBM) Delta, we apply a nonparametric seasonal-trend decomposition procedure (STL) to observations compiled from 19852005 in Bangladesh. Seasonality dominates observed variance in groundwater levels but declining groundwater levels $(>1 \mathrm{~m} / \mathrm{yr})$ are detected in urban and peri-urban areas around Dhaka as well as in north-central, northwestern, and southwestern parts of the country $(0.1-0.5 \mathrm{~m} / \mathrm{yr})$ where intensive abstraction of groundwater is conducted for dry-season rice cultivation. Rising groundwater levels $(0.5-2.5 \mathrm{~cm} / \mathrm{yr})$ are observed in the estuarine and southern coastal regions. This novel application of the STL procedure reveals, for the first time, the unsustainability of irrigation supplied by shallow aquifers in some areas (e.g., High Barind Tract) of the GBM Delta and the hydrological impact of potential seawater intrusion of coastal aquifers associated with sea-level rise. Our findings provide important insight into the hydrological impacts of groundwater-fed irrigation and sea-level rise in other Asian mega-deltas where monitoring data are limited.
\end{abstract}

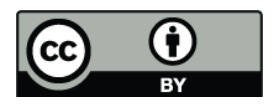

Correspondence to: $\mathrm{M}$. Shamsudduha (m.shamsudduha@ucl.ac.uk)

\section{Introduction}

Asian mega-deltas feature regionally extensive shallow aquifers within sedimentary sequences deposited over the last $10 \mathrm{ka}$ (Benner et al., 2008). Groundwater levels in shallow aquifers (depth $<80 \mathrm{mbgl}$ ) underlying Asian megadeltas (Fig. 1) are highly seasonal as a result of intensive precipitation during the annual monsoon (Klump et al., 2006; Mukherjee et al., 2007; Larsen et al., 2008; Norrman et al., 2008; Berg et al., 2008). Seasonal fluctuations vary considerably both at spatial and temporal scales and range from 2-8 m in the Ganges-Brahmaputra-Meghna (GBM) Delta (BGS and DPHE, 2001), 2-5 $\mathrm{m}$ in the Red River Basin (Norrman et al., 2008), 2-8 $\mathrm{m}$ in the Mekong Basin (Benner et al., 2008; Berg et al., 2008), and 1-5 $\mathrm{m}$ in the Chao Phraya Basin (Suwanlert, 2004). Groundwater abstraction for dry-season irrigation which has taken place since 1970s in the GBM Delta (WARPO, 2000) and more recently in the Irrawaddy Basin and Mekong Delta (Dawe, 2005; FAO, 2006), serves to increase seasonality in shallow groundwater levels. The highly seasonal nature of the shallow groundwater systems in Asian mega-deltas complicates resolution of trends in groundwater levels and, hence, groundwater storage.

Statistical methods for trend analysis vary from simple linear regression to more advanced parametric and nonparametric methods (Helsel and Hirsch, 2002). Classical approaches such as the Mann-Kendall trend test (Mann, 1945; Kendall, 1975) and its seasonal counterpart have been widely used for testing trends in hydrological time-series (Hirsch et al., 1982; Aziz and Burn, 2006; Thas et al., 2007). The MannKendall and Seasonal Kendall tests are, however, unable to resolve trends adequately in a time series characterized by serial dependence (Hirsch and Slack, 1984; Hamed and Rao, 1998). A further difficulty is that most standard methods

Published by Copernicus Publications on behalf of the European Geosciences Union. 


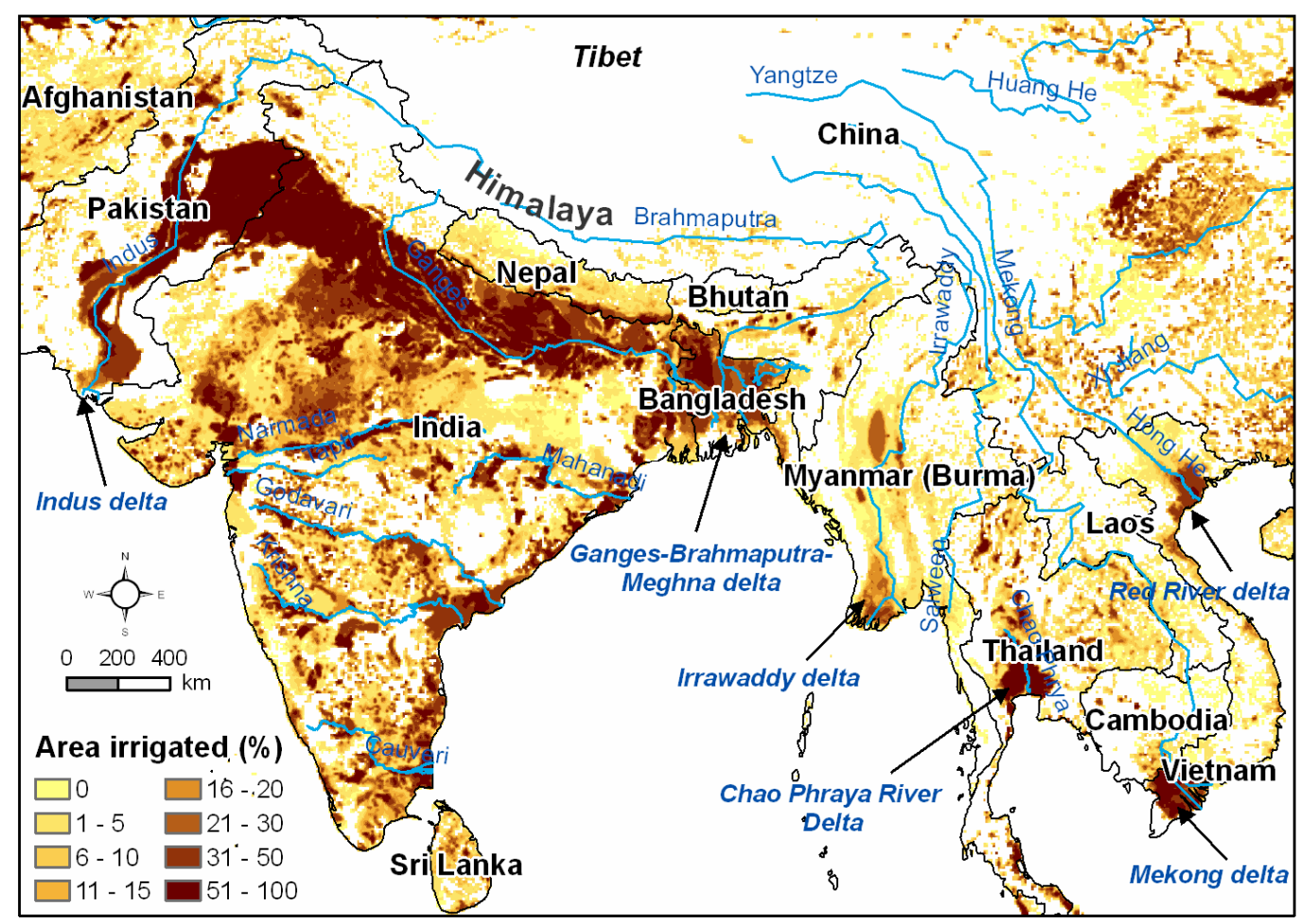

Fig. 1. General location of the mega deltas of south and southeast Asian countries. Areas in these deltas that are equipped for irrigation (shown in color shades) are taken from the digital global map of irrigation by Siebert et al. (2006). Areas under irrigation are shown as percentages of the surface area. In the GBM delta, groundwater-fed irrigation accounts for 30\% of the country's total land area. Irrigation is, however, mainly conducted from surface water in many of these mega deltas in Asia.

are designed to detect monotonic trend in a series (Hipel and McLeod, 1994). This restriction limits their usefulness where temporary variations of a long-term trend and change in seasonality are important in assessing the impacts of shortterm climate change and anthropogenic activities (Qian et al., 2000). A disadvantage, which is arguably more serious, is that traditional trend test procedures are designed to identify trends in the time series but not to characterize them. A systematic characterization of variability permits an evaluation of hydrodynamic responses. Decomposition of a groundwater level time series into trend, seasonal and irregular components enables an understanding of the processes that control flow within groundwater systems (Taylor and Alley, 2001). In this study, we resolve trends in shallow groundwater levels within the GBM Delta by applying linear regression and a seasonal-trend decomposition procedure to a groundwaterlevel database of 1.8 million weekly records from 1267 monitoring wells over the period of 1985-2005 in Bangladesh.

\section{The Ganges-Brahmaputra-Meghna Delta}

The GBM Delta is situated in the Bengal Basin which lies in front of the Himalayan foredeep (Fig. 1; Goodbred and Kuehl, 2000). River flow in this region is highly seasonal, with $80 \%$ of the annual discharge occurring during the four months of southwestern monsoon (Coleman, 1969). The modern Bengal Basin comprises about $100000 \mathrm{~km}^{2}$ of lowland floodplain and delta plain and is bound by Tertiary highlands related to the uplift of the Himalayas (Goodbred and Kuehl, 2000). Global climatic changes, physical and chemical weathering in the Himalayas and subsidence in the Bengal Basin interacted to control the Quaternary alluvial sedimentation and thus hydrogeology of this region (BGS and DPHE, 2001; Ravenscroft et al., 2005). Highly productive aquifers occur within these thick unconsolidated alluvial sediments of the Pleistocene and Holocene ages that were deposited by the GBM river system (Shamsudduha and Uddin, 2007). Aquifers occur at relatively shallow depths (5$20 \mathrm{mbgl}$ ) beneath the broad alluvial floodplain, alluvial fan and deltaic deposits, and at comparatively deeper depths (15$45 \mathrm{mbgl}$ ) underlying the Madhupur clay and Barind clay deposits in Bangladesh (Ravenscroft et al., 2005). Aquifers that are found within the geologically complex bedrock terrains in eastern parts of the country are of variable thickness and depth. Recent alluvium and upper part of the Dupi Tila sand of Pliocene-Pleistocene age form shallow aquifers which are generally located within the depth of $100 \mathrm{~m}$ below surface (Ahmed et al., 2004). In Bangladesh, younger or recent alluvium and fan deposits are the focus of shallow groundwater development (UNDP, 1982; BGS and DPHE, 2001). 
The hydrodynamics of the GBM deltaic aquifers has been substantially modified by groundwater abstraction (Agrawala et al., 2003; Harvey et al., 2006; Stute et al., 2007; Shamsudduha and Uddin, 2007). In Bangladesh, groundwater is widely used for domestic, industrial and agricultural purposes but dry-season irrigation for high-yielding Boro rice cultivation withdraws the most groundwater in Bangladesh (BADC, 2003). Intensive abstraction for irrigation (25-75 wells per $\mathrm{km}^{2}$ of irrigated land) occurs in many areas of northwestern Bangladesh and began during the late 1960s to early 1970s with the installation of deep (depth $>80 \mathrm{mbgl}$ ) tubewells (DTW) by the Bangladesh Water Development Board (BWDB) (BADC, 2003). Initially, irrigation from groundwater was provided by these DTW in addition to surface water irrigation with low-lift pumps (LLP) and traditional methods (BADC, 2003). During the 1980s and 1990s the government, with support from international organizations, installed thousands of shallow (depth $<80 \mathrm{mbgl}$ ) irrigation tubewells (STW) following the recognition of large quantities of groundwater at relatively shallow depths (BGS and DPHE, 2001; World Bank, 2005). The regional-scale impact of abstraction on shallow groundwater levels has yet to be assessed. The impact of sea-level rise on groundwater levels in coastal regions is also unclear.

\section{Data sets and statistical methods}

\subsection{National groundwater level database of Bangladesh}

We compiled a national database of 1.8 million records of weekly groundwater level data from a dense network (one per $105 \mathrm{~km}^{2}$ ) of 1267 monitoring wells that have been managed by Bangladesh Water Development Board (BWDB) since the early 1970s. Depth from the well head to groundwater level at each station is referenced to a common horizontal datum known as the Public Works Datum (PWD), originally set approximately at the mean sea level (msl) with a vertical error of $\pm 0.45 \mathrm{~m}$. During the $1960 \mathrm{~s}$ most of these monitoring wells were dug wells; many of these were subsequently replaced by piezometers. The total number of monitoring wells that operated from 1961-2006 is 2154; 735 were dug wells and 1419 were piezometers of variable depths ranging from 3.9 to $352 \mathrm{mbgl}$ (mean depth $24 \mathrm{mbgl}$ ). Most dug wells have now been replaced by piezometers at the same location; faulty piezometers have also been replaced throughout the recording period. In some cases, newly installed piezometers were drilled deeper or shallower than those they replaced. The total number of unique well locations in the present database is 1267 . In our analyses, we treat each replacement well as a separate monitoring station to avoid potential problems associated with spurious trends due to well substitution. In the newly compiled weekly groundwater level database, there are 1189 piezometers and $78 \mathrm{dug}$ wells. We used the " $R$ " statistical language (R Development

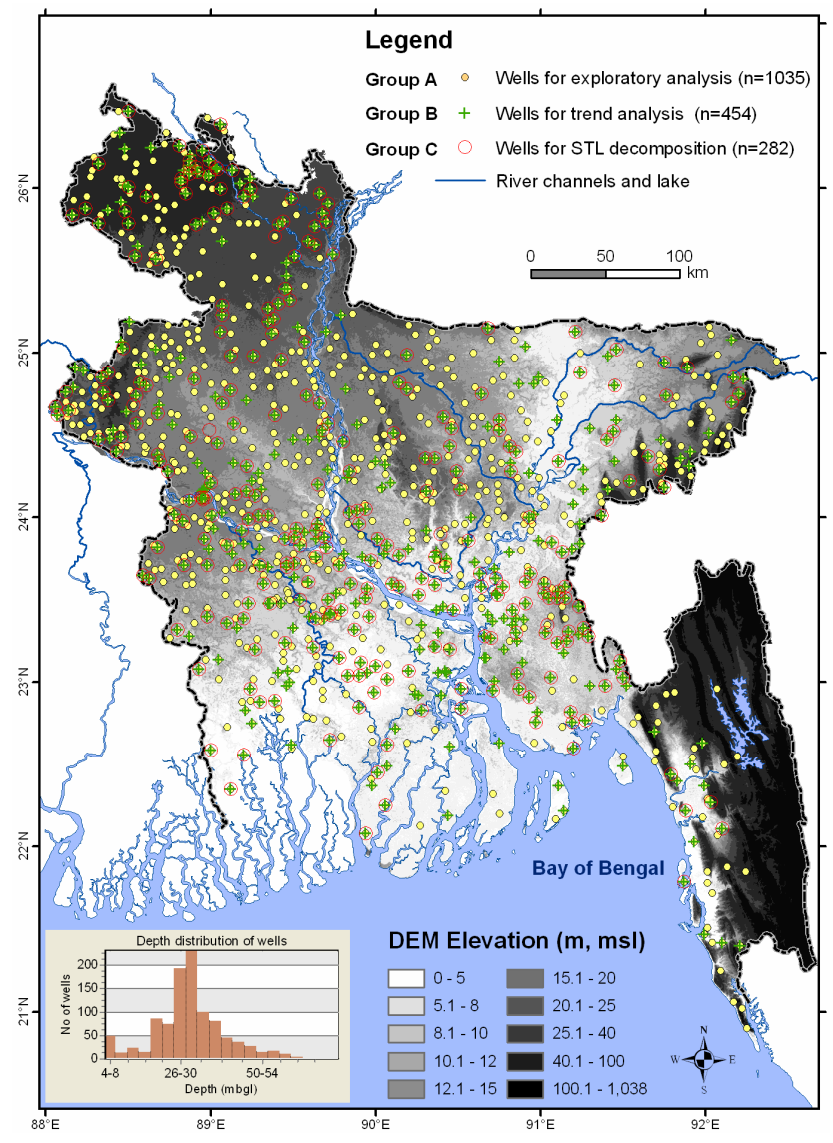

Fig. 2. Distributions of groundwater level monitoring stations in Bangladesh (Group A, B and C) imposed on a $90 \mathrm{~m}$ resolution digital elevation model derived from the Shuttle Radar Topography Mission (SRTM). Depth distribution of monitoring wells is shown in the histogram (inset).

Core Team, 2007) to read and re-structure groundwater level data from two original data formats (i.e., flat text-file and Microsoft Access database) maintained by BWDB. All waterlevel records were subjected to systematic quality control procedures. Wells with unreliable and only a few groundwater level data were flagged and discarded from subsequent analyses. Wells with no available information on the depth to the well screen and wells with more than $50 \%$ of missing records were also discarded.

\subsection{Data sets and exploratory analyses}

Three groups of monitoring wells were defined for the statistical analyses reported below. Group A comprises 1035 shallow monitoring wells (66 dug wells and 969 piezometers) yielding 1.1 million, quality controlled, groundwaterlevel observations that were used for exploratory analyses (Fig. 2). The record lengths in Group A wells range from 7 to 41 years, with a mean of 22 . Exploratory analyses were restricted to the period from 1985-2005 in order to 
be consistent with the dominant observation period of the majority of monitoring wells. All wells in Group A have $<20 \%$ missing data with a mean of $5.5 \%$ for the entire group. Group B is a subset of 454 wells from Group A that have been specially selected for trend analysis because their record lengths extend over the entire period from 1985 to 2005; the mean proportion of missing data is $5.9 \%$. Group $\mathrm{C}$ is a subset of Group B comprising 282 wells for which missing records (mean 5\%) are of sufficiently short duration and thus could be imputed using a simple linear interpolation method. Where data in Group C wells were found missing either in the average driest (April) and or the wettest (September) months of a particular year, the missing value was imputed by taking the mean of groundwater levels of the relevant period from two adjacent years. Group $\mathrm{C}$ wells were used for STL decomposition analysis as this method requires time series without gaps.

Exploratory analyses of the Group A wells investigated the general distribution of groundwater levels across Bangladesh. Groundwater levels for individual wells, selected to reflect variations in surface geological units, were plotted to investigate variations in groundwater-level time series in different regions. Time series plots of various summary statistics at monthly, annual and decadal timescales were also produced to develop a preliminary assessment of trends. For each Group A well, the median groundwater level was calculated for each month to summarize the seasonal structure in the record.

\subsection{Linear regression for trend analysis}

The exploratory analyses of Group A wells provided an initial impression of seasonality and trends in the groundwater series. It is of particular interest to test for and characterize trends in the series, for example to examine the sustainability of current abstraction levels. To this end, an initial assessment of trends over the period from 1985-2005 was carried out using linear regression applied to annual time series at each Group B monitoring site for direct comparison of results. To investigate the possibility that trends may be seasonally varying, three different annual series were analyzed at each site: the mean, 5th and 95th percentiles of each year's observations. Trends in 5th percentiles correspond roughly to changes during the dry period, and trends in 95th percentiles to changes in the wet season groundwater levels. The use of percentiles, rather than annual maxima and minima, avoids problems associated with outliers and data errors.

\subsection{Trend and seasonality decomposition with STL method}

Despite widespread application of linear regression for trend analysis, this procedure does not provide accurate assessments of nonlinear trends in borehole groundwater levels. In the analysis of linear trends in Group B wells, we treated mean and seasonal extremes separately yet it is preferable to develop an integrated description of change in groundwater levels over the entire time series. We applied a nonparametric time series decomposition method known as "Seasonal-Trend decomposition procedure based on Loess (STL)" (Cleveland et al., 1990) to resolve trends and seasonality in groundwater levels at each Group C monitoring well. Each time series of groundwater level records was decomposed using the STL decomposition method (Eq. 1) in the $R$ statistical language as:

$Y_{t}=T_{t}+S_{t}+R_{t}$

where $Y_{t}$ is the groundwater level at time $t, T_{t}$ is the trend component; $S_{t}$ is the seasonal component; and $R_{t}$ is an irregular (residual) component.

The STL method consists of a series of smoothing operations with different moving window widths chosen to extract different frequencies within a time series, and can be regarded as an extension of classical methods for decomposing a series into its individual components (see Sect. 2.6 in Chatfield, 2003). STL uses the locally weighted regression (LOESS) technique that was first proposed by Cleveland (1979) and later modified by Cleveland and Devlin (1988). The nonparametric nature of the STL decomposition technique enables detection of nonlinear patterns in long-term trends that cannot be assessed through linear trend analyses (Sect. 3.3).

For STL decomposition, it is necessary to choose values of smoothing parameters to extract trend and seasonal components. The choice of the seasonal smoothing parameter determines the extent to which the extracted seasonal component varies from year to year: a large value will lead to similar components in all years whereas a small value will allow the extracted component to track the observations more closely. Similar comments apply to the choice of smoothing parameter for the trend component. We experimented with several different choices of smoothing parameters at a number of contrasting sites; visualization of the results suggested that the overall structure of time series at all sites could be captured reasonably using window widths of 7 years for the seasonal component and 5 years for the trend. The smoothing parameters were therefore fixed at these values for all subsequent STL analyses.

\section{Results}

\subsection{Exploratory statistics and spatio-temporal distribu- tion of groundwater levels}

Figure 3 shows groundwater levels for selected wells, along with the corresponding seasonal and annual distributions. These plots reveal both seasonality and long-term trends in groundwater levels. The results from all wells show that 

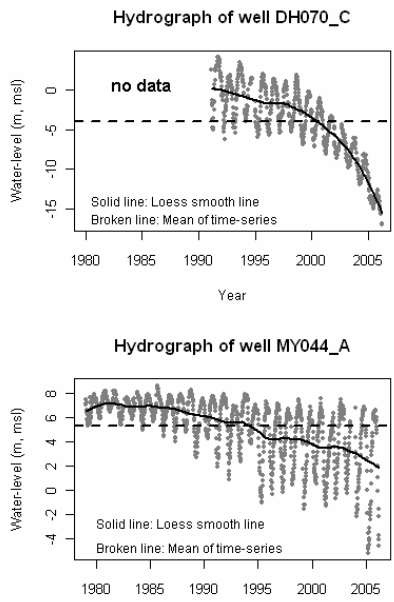

Year

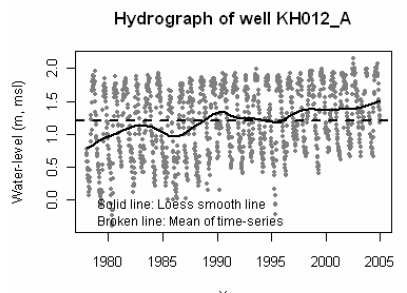

Year
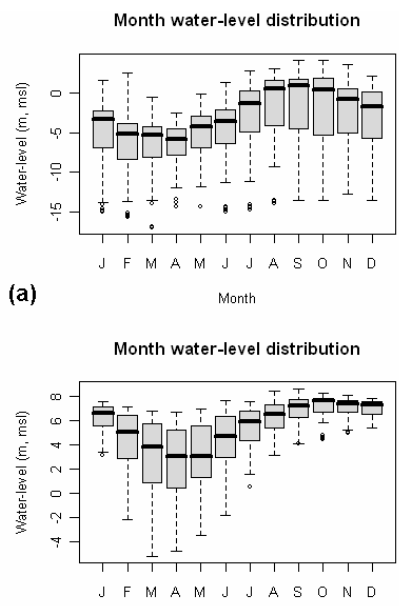

(b)

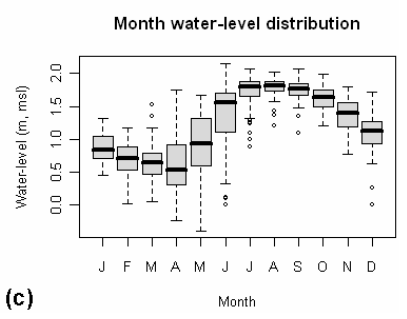

Fig. 3. Groundwater levels and boxplots of monthly groundwater level distributions for three broadly representative monitoring wells in Bangladesh: a rapidly declining well (a), a steadily declining well (b), and a well with slightly rising trend (c). Seasonal variations in groundwater levels of these three wells are shown as boxplots drawn next to the groundwater level plot of each well.

the relative magnitude of each component varies considerably across the country. Long-term patterns include declining, stable, and rising trends in groundwater levels. Figure 3a shows data from a well (DH070-C) with a rapidly declining groundwater level and decreasing seasonality which is generally observed in the central part of Bangladesh in and around the capital city of Dhaka. The monthly boxplots at this location show that overall variability in groundwater levels is highest during the wet season. The groundwater-level plot is, however, dominated by the long-term trend. For another well (MY044-A) in the Old Brahmaputra river floodplain of the northeastern Bangladesh a steadily declining trend occurs mainly during the dry season (Fig. 3b) and, in contrast to DH070-C, seasonality is the dominant component of the series. Site KH012-A reveals another distinct pattern (Fig. 3c) consisting of a slightly rising trend with a smaller overall variation than other wells, and enhanced variability during the early monsoon. This site is located in a southern coastal area of the Bagerhat district. To visualize the regional structure of the groundwater levels, Fig. 4 shows maps of the median levels from every monitoring well in Group A during the driest month (April) and the wettest month (September). General distributions of groundwater levels in the coun-

try broadly conform to topography. Seasonal groundwater flow-fields at the regional scale are shown in Fig. 4 and Supplementary Fig. I (http://www.hydrol-earth-syst-sci.net/13/ 2373/2009/hess-13-2373-2009-supplement.zip, showing the median groundwater levels for each month of the year); presented contours naturally mask localized groundwater flowfields (hundreds of $\mathrm{m}$ to tens of $\mathrm{km}$ ) as each monitoring well represents a mean area of $105 \mathrm{~km}^{2}$. From these regionalscale groundwater contours the shallow groundwater flows from the northwest and north-eastern areas towards the central region and then in southern and southwestern directions discharging into the Bay of Bengal.

Figure 4 shows that spatial distributions in groundwater levels between April and September are very different in the western and north-central areas (where the annual fluctuations of water-tables are 6-9 m) from those in the southern GBM delta and the north-eastern floodplain areas (where annual fluctuations levels rarely exceed $3 \mathrm{~m}$ with a mean of $1.5 \mathrm{~m}$ ). In the central part of the country (around Dhaka city) a regional cone of depression ( $\sim 50 \mathrm{~km}$ in diameter) is observed throughout the year. During the dry season (see the April map in Fig. 4), the cone expands northwards. Despite these regional groundwater flow patterns, temporal variations at the local-scale $(50-100 \mathrm{~km})$ are observed in the monthly median groundwater-levels throughout the country (Supplementary Fig. I, http://www.hydrol-earth-syst-sci.net/13/ 2373/2009/hess-13-2373-2009-supplement.zip). Relatively higher levels are observed along the major rivers and close to their confluences, even during dry months when groundwater levels decline due to intensive abstraction for irrigation.

\subsection{Trends in shallow groundwater levels}

Long-term (1985-2005) trends in groundwater levels of shallow aquifers across Bangladesh are shown in Fig. 5. Panels $(\mathrm{a}-\mathrm{c})$ show contours of linear trends $(\mathrm{cm} / \mathrm{yr})$ during the dry season (5th percentile), wet season (95th percentile), and in overall (annual mean) time series. Panel (d) will be discussed below. All of the maps show generally declining trends in most parts of Bangladesh, although the magnitudes of these trends vary spatially.

Strong declining trends $(0.5-1 \mathrm{~m} / \mathrm{yr})$ in dry-period groundwater levels are observed in the central part of the country surrounding the Dhaka city. Moderately declining trends $(0.1-0.5 \mathrm{~m} / \mathrm{yr})$ occur in western, northwestern, and northeastern areas. In the northern piedmont areas and floodplains of the major rivers, magnitudes of declining trends are low $(0.01-0.05 \mathrm{~m} / \mathrm{yr})$. Stable or slightly rising trends $(0-0.1 \mathrm{~m} / \mathrm{yr})$ are generally observed from the Meghna estuary to the southern coastal areas in the country. A similar overall pattern is seen during wet periods (Fig. 5b) except in the northern piedmont areas, southwestern delta plains and southern coastal areas where wet period trends are slightly rising or stable. 

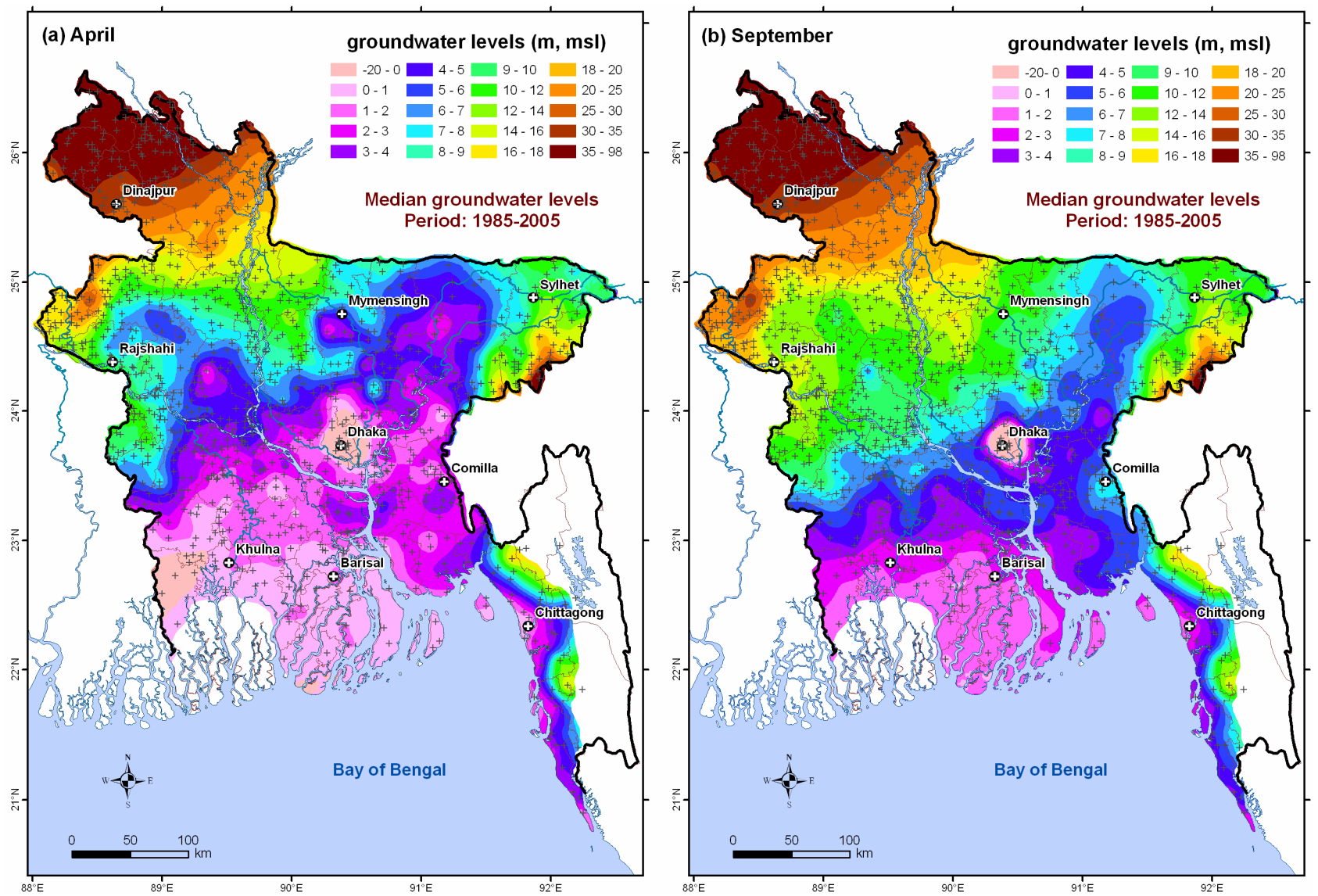

Fig. 4. Median groundwater levels for April (end of dry season) and September (end of monsoon season) over a period of 21 years. Groundwater levels are referenced to the mean sea level (msl).

Similar to long-term trends during dry and wet periods, declining trends in annual mean groundwater levels are observed in the central, northwestern, and northeastern parts (Fig. 5c). Relatively stable to rising mean groundwater levels are detected in the northern piedmont, floodplains of major rivers, and deltaic plains. Generally declining groundwater levels are observed in the complex geological terrain of the eastern part of Bangladesh.

\subsection{Spatial variability in trend and seasonal components}

To obtain a more complete picture of the regional groundwater time series structure, we focus on the results of STL analyses. First, a representative STL decomposition (for monitoring well RJ039-B) is shown in Fig. 6. In this example, we observe a decreasing seasonality over time and a declining trend in the time series. The STL method improves on the previous linear regression analyses both by allowing a more flexible representation of the underlying trend, and by considering all aspects of the time series simultaneously.

For the purpose of visualizing the regional structure in STL-derived trends, it is convenient to reduce each one to a single number. Here, for each well an index of overall annual change has been defined as $52\left(T_{n}-T_{1}\right) / n$, where $n=52 \times 21$ is the number of weeks of record in the analysis period 1985-2005 and $T_{t}$ is the value of the STL trend component in the $t$-th week of the record as defined above. Panel (d) in Fig. 5 shows a map of the long-term trends calculated in this way. Overall, the pattern is very similar to that derived in Fig. 5c using linear regression, although fewer wells $(n=282)$ were used in the STL analysis due to more stringent data requirements. The STL trends are, however, more realistic than trends estimated by linear regression for the reasons given above.

To obtain further insight into the regional groundwater dynamics, it is of interest to compare the magnitudes of the trend, seasonal and irregular components at each monitoring location. To do this we have expressed the sample variance of each component as a percentage of the variance of the original groundwater level time series over the 1985-2005 period. Figure 7a maps the variances in the original series. Higher variances in groundwater levels $\left(5-30 \mathrm{~m}^{2}\right)$ are observed in the north-central, northwestern and southwestern parts where mean annual fluctuations of groundwater levels are high (3$8 \mathrm{~m}$ ). Smaller variances are observed in the north, northeastern, southern delta plains and estuarine areas. 

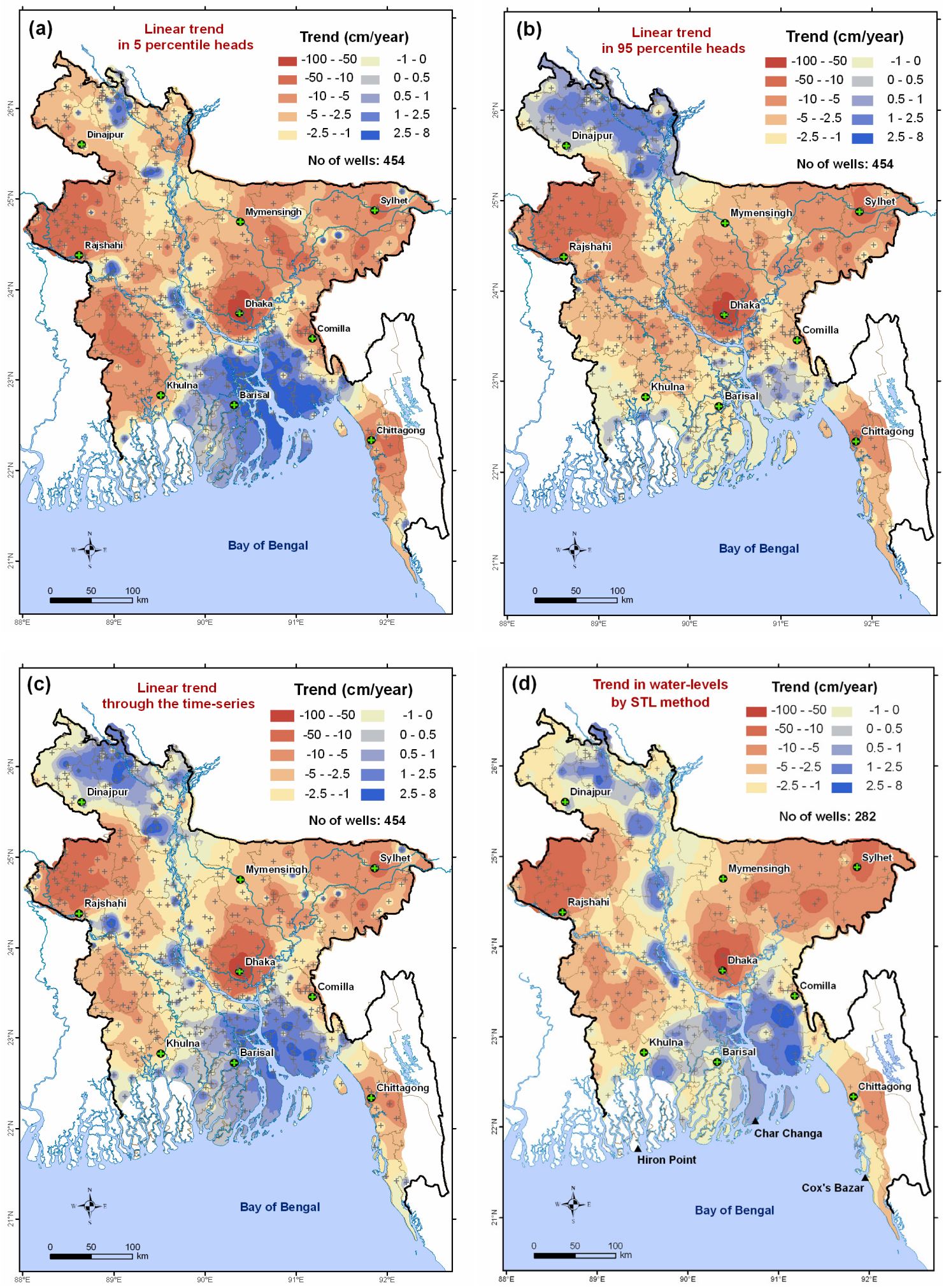

Fig. 5. Trends in groundwater levels between 1985 and 2005. Linear trends in the dry-period groundwater levels (5th percentiles of observations in each year) are shown in (a), trends in the wet-period groundwater levels (95th percentiles) are shown in (b), linear trends in annual means are shown in (c), and nonparametric trends calculated from the long-term trend component derived from an STL decomposition are shown in (d). Trends in sea-level at three locations in coastal regions of Bangladesh calculated by Singh (2002) are shown in (d). 

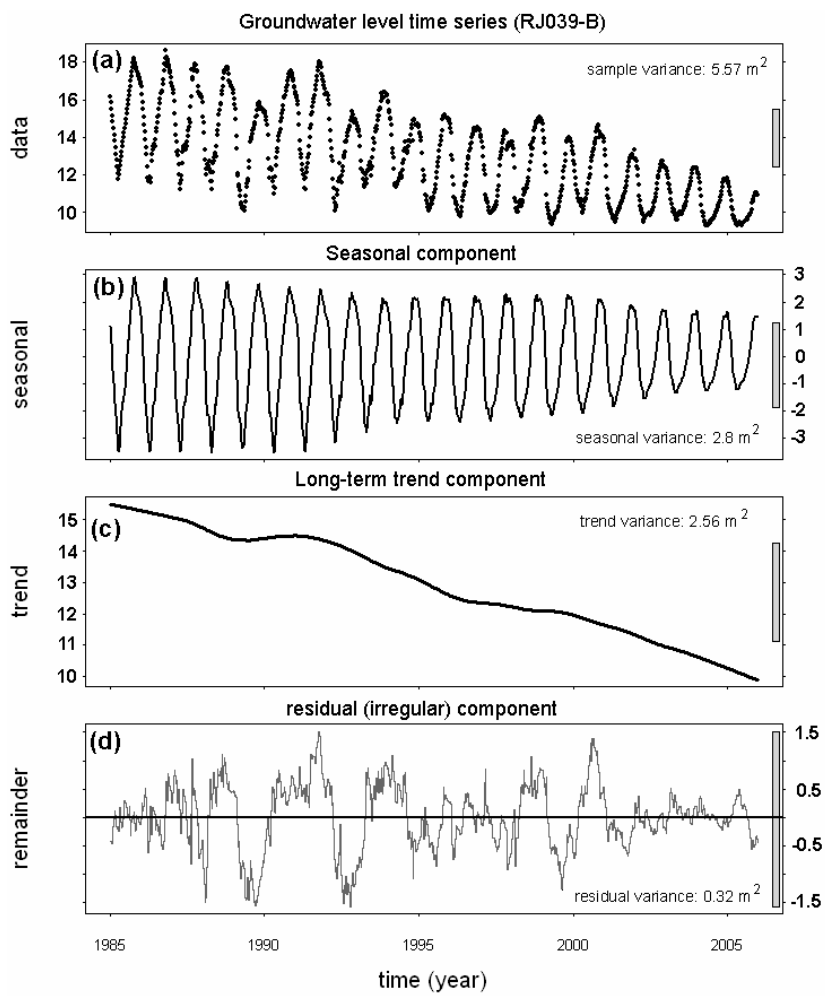

Fig. 6. STL decomposition of the groundwater level time-series data $(\mathrm{m}, \mathrm{msl})$ for the monitoring well RJ039-B. The original time series of groundwater level data in (a). Seasonal and trend components as decomposed from time series by STL are shown in (b) and (c). Residual (irregular) component of the time-series is shown in (d). The bars at the right-hand ends of the plots provide a comparison of the vertical scales.

Figure $7 \mathrm{~b}$ shows the contribution of the STL seasonal components to the overall variance across the country. Generally, seasonality is the primary component of variance in groundwater levels except in northeastern and southeastern regions of the country. Groundwater level monitoring wells that are dominated by the seasonal component $(>80 \%$ of variance) occur mainly in the upper Ganges and Brahmaputra floodplains. Seasonality explains $70-80 \%$ of the variance in groundwater levels in the northwestern and southeastern regions. Seasonality is the least important component in the central (surrounding Dhaka city), and eastern (Sylhet depression and Chittagong Hill Tracts) areas of Bangladesh.

Figure 7c shows the contribution of the STL trend components to the overall variance. Trend is the major component of variance in several locations. Higher percentages of trend components are concentrated in the central, northwestern, and north-eastern parts of Bangladesh. Although trends are detected in a large area of the north-east (Sylhet depression and Chittagong Hill Tracts), total variances of groundwater levels are rather small $\left(<0.6 \mathrm{~m}^{2}\right)$ here. In contrast, areas with elevated trend variances are also observed in the northwestern parts (Higher Barind Tract in greater Rajshahi district) where mean annual groundwater fluctuations are high $(>5 \mathrm{~m})$.

The median percentage of variance due to irregular components in groundwater levels is about $18 \%$ in the analyzed 282 monitoring wells (Fig. 7d). High irregular variances in groundwater levels coincide with anomalous seasonal extremes in groundwater levels that result from exceptional flood events and groundwater abstractions. Higher percentages of irregular components in groundwater levels are observed in the south-eastern and northern most parts of the country where annual fluctuations in groundwater levels are relatively smaller than the north-central and northwestern parts.

Spatial variations in groundwater level variance and its decomposition into various time series components are represented in two regional transects (Figs. 7a, and 8). The N-S transect shows variations in seasonality, trend and irregular components from piedmont areas down to the deltaic region, through central floodplains of the Brahmaputra river; and the W-E transect shows the variations from the northwestern irrigation districts to eastern parts through Dhaka city. Figure 8 shows that along both transects, seasonality is the major component of groundwater variance; however, trends dominate in the northwestern agricultural region and around Dhaka city. The irregular component explains approximately $15-20 \%$ of the variance in groundwater levels throughout the country. Irregular components are higher in the eastern hilly areas where aquifers are complex in nature.

\section{Discussion}

\subsection{Trends in groundwater levels in the Ganges-Brahmaputra-Meghna Delta}

Our analyses show that shallow groundwater in the GBM Delta is highly dynamic with strong seasonality and trends of variable magnitude. Both parametric and nonparametric procedures reveal long-term trends in shallow groundwater levels throughout the country. Seasonality dominates the variance in groundwater levels in shallow aquifers beneath the Ganges and Brahmaputra floodplains where seasonal fluctuations in water-levels are primarily driven by major riverlevels and abstractions for irrigation (Aggarwal et al., 2000; BGS and DPHE, 2001). Declining trends during the wet season, particularly in central $(0.5-1 \mathrm{~m} / \mathrm{yr})$ and northwestern $(0.1-0.5 \mathrm{~m} / \mathrm{yr})$ regions, indicate that shallow aquifers in these areas are not fully recharged each year during the monsoon season. As a result, shallow groundwater storage is declining. This critical observation rejects the widely held assumption that shallow aquifers attain the apparent "full condition" every monsoon throughout Bangladesh (UNDP, 1982; WAPRO, 2000; Aggarwal et al., 2000; BGS and DPHE, 2001; Harvey et al., 2006). 

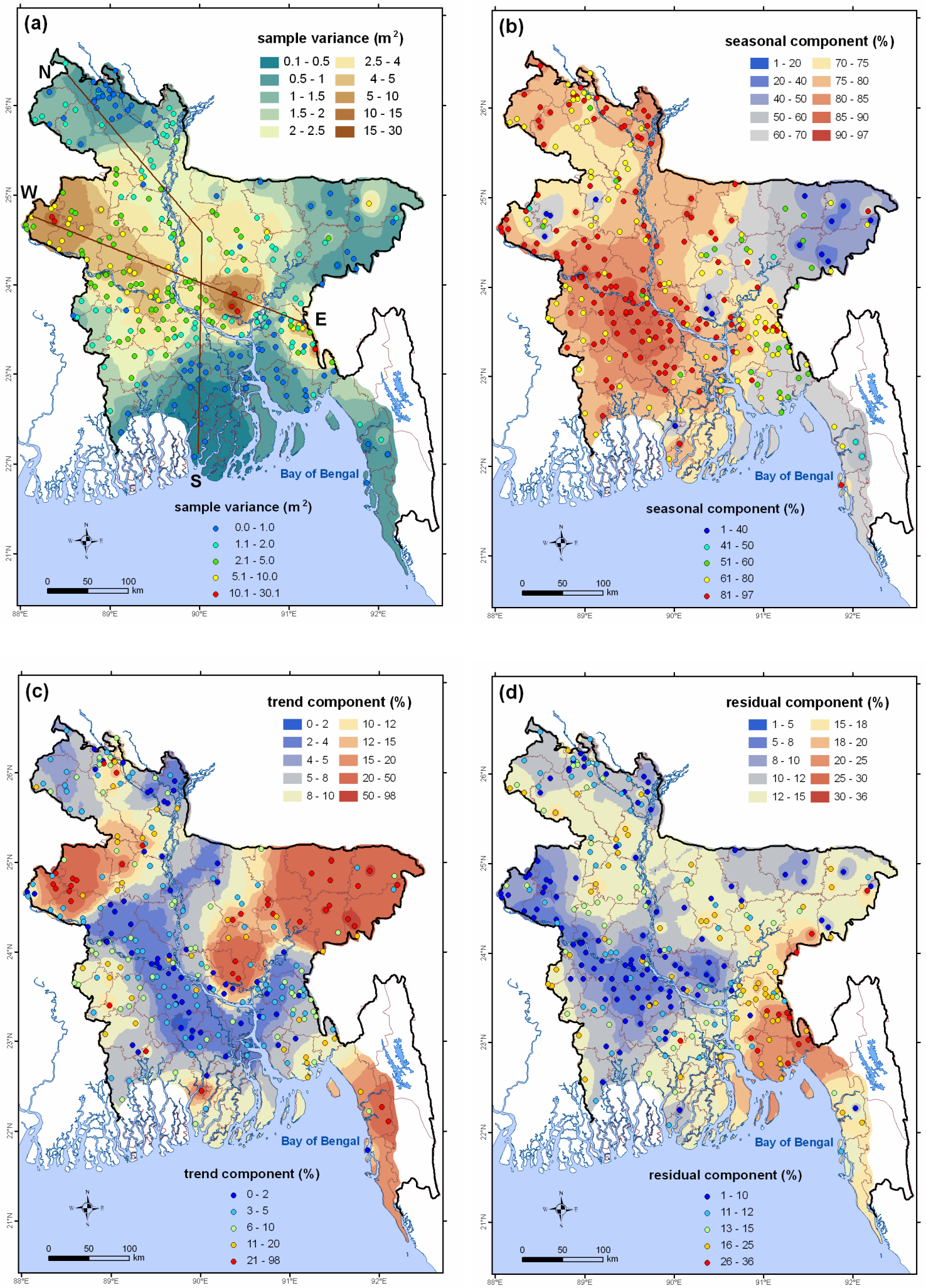

Fig. 7. Variance of groundwater level time series for Group-C wells (a); relative proportions of groundwater level variance contributed by seasonal, trend and irregular components are shown in (b-d), respectively. Relative proportion of variance in groundwater levels explained by all time series components along two profiles lines (N-S and W-E) on Fig. 7a are shown in Fig. 8. 


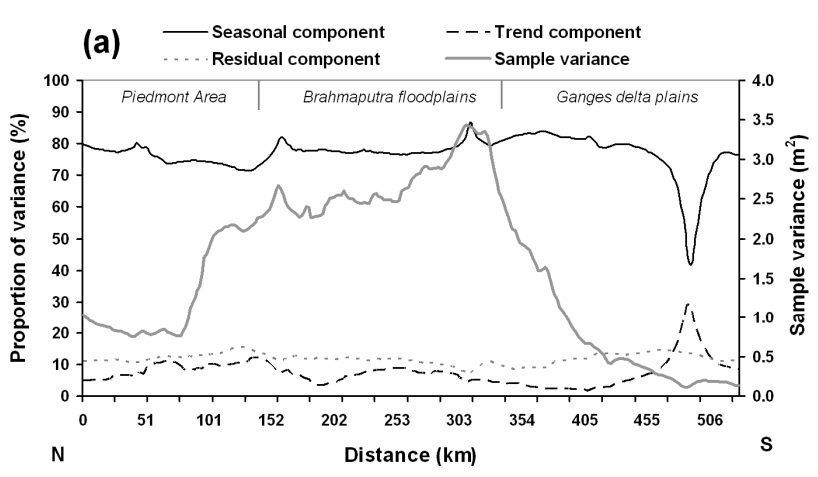

(b)

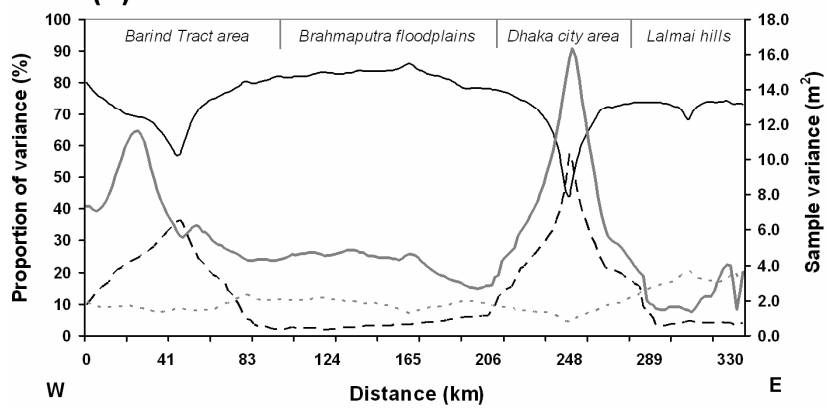

Fig. 8. Sample variances and proportions of variances explained by various components of the groundwater level time series data along two transects as shown in Fig. 7a; N-S profile shows variance in the groundwater level data (a); proportions of time series variances contributed by seasonality, trend and irregular components; seasonality is the dominating time series component in the Piedmont and Brahmaputra floodplain areas; W-E profile (b) shows that trend components in the Barind Tract and central parts of Bangladesh are dominant where seasonal components are relatively less stronger.

The spatial structure of deduced trends reflects the balance between abstraction and surface geology which acts as a key control on the magnitude of groundwater recharge. From 1979 to 2003, groundwater-fed irrigation for dry season rice cultivation in Bangladesh increased by approximately 875 million cubic meters (MCM) each year (BADC, 2003) elevating annual rice production from 11.9 megatonnes (Mt) in 1975 to $27.3 \mathrm{Mt}$ in 2006-2007 (Bangladesh Bureau of Statistics, 2008). Although records of groundwater usage for irrigation are not available, we provide an approximation of the spatial distribution of groundwater abstraction based on the fraction (as a percentage) of land in each of the country's 64 districts that was irrigated by both shallow and deep irrigation pumps in 2003 (Fig. 9). Nationally, a total of 924023 STWs were used to irrigate about $24094 \mathrm{~km}^{2}$ of agricultural land accounting for approximately $60 \%$ of irrigated land whereas irrigation using DTWs comprised $15 \%$.

Our observations indicate that areas of intensive abstraction for irrigation exhibit declining trends in long-term groundwater levels in Bangladesh. A key exception is in the district of Dhaka where the shallow aquifer is overlain by

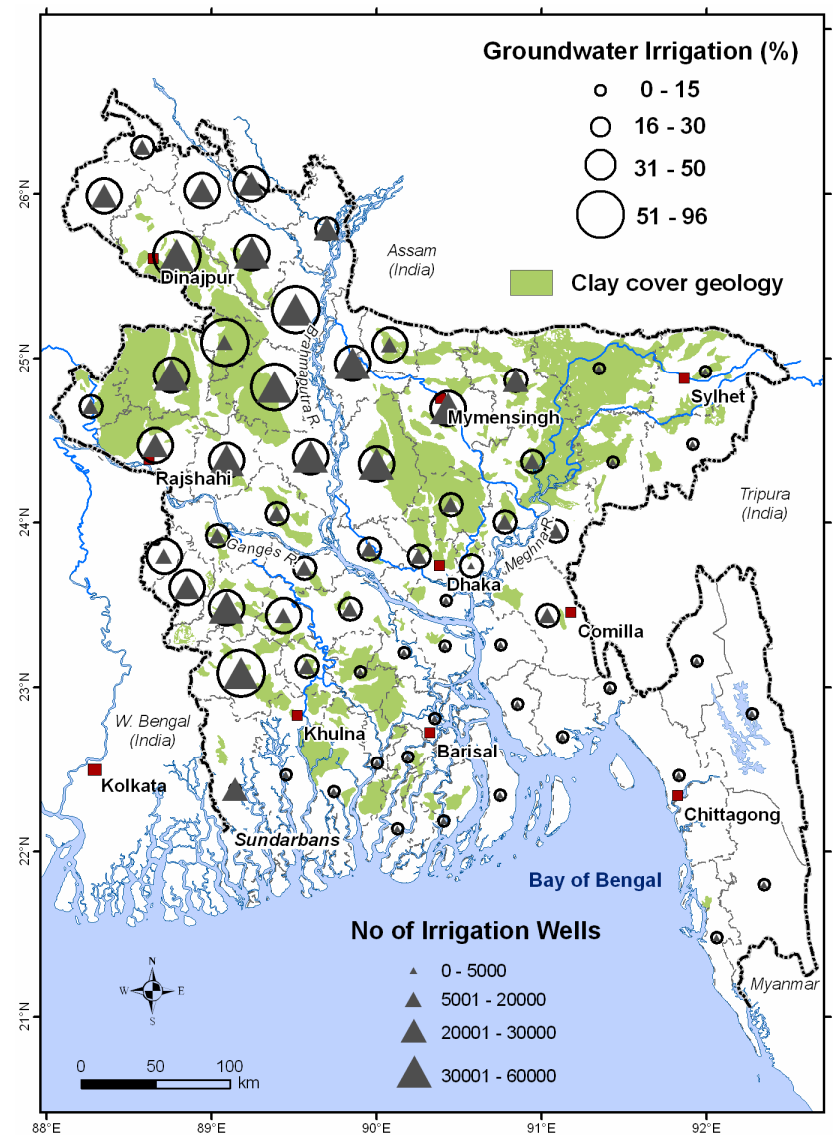

Fig. 9. Percentage of land in each of the 64 districts (broken gray lines) in Bangladesh irrigated with groundwater in 2003 (BADC, 2003). Total numbers of shallow and deep tubewells operated in each district in 2003 are also shown. Low-permeable regionally extensive surface geological units are shown in the background.

the Madhupur clay formation (Ahmed et al., 1999). Here, there is little abstraction for irrigation in peri-urban areas but annual abstraction for domestic and industrial purposes is $\sim 750 \mathrm{MCM}$ (Hoque et al., 2007) and substantially exceeds total annual recharge of 380-480 MCM in the Dhaka district (UNDP, 1982; Karim, 1984). This high groundwater deficit is responsible for the rapid decline $(>1 \mathrm{~m} / \mathrm{yr}$ ) in groundwater levels. Elsewhere in Bangladesh, the magnitude of declining shallow groundwater storage in northwestern (i.e., Barind Tract) and north-central (i.e., Madhupur Tract) regions (Fig. 9) relates not only to the intensity of abstraction but also low in areas of clay cover where rates of rainfall-fed recharge are constrained by the low hydraulic conductivity $(0.01 \mathrm{~m} /$ day $)$ of this surface geology.

\subsection{Rising groundwater levels and sea-level rise}

Rising trends in groundwater levels $(0.5-2.5 \mathrm{~cm} / \mathrm{yr})$ observed from 1985-2005 in the Meghna estuary and coastal regions of Bangladesh, coincide with rising sea levels reported by 
several studies (Alam, 1996; Singh et al., 2000; Singh, 2002; Mohal et al., 2007). Observed sea levels from 1977-1998 at three locations (see Fig. 5d) reveal that mean rates of sealevel rise range from $0.4-0.8 \mathrm{~cm} / \mathrm{yr}$ (Singh, 2002). These rates are much higher than the average rate of global sea level rise of $0.18 \mathrm{~cm} / \mathrm{yr}$ for the 20th century (IPCC, 2007) and arise from regional factors such as sediment load, basin tectonics and differential subsidence $(2-15 \mathrm{~mm} / \mathrm{yr})$ of the GBM delta (Worm et al., 1998; Goodbred and Kuehl, 2000; Steckler et al., 2007). As sea levels rise, shallow groundwater in coastal areas is elevated through an overall rise in the position of the freshwater-seawater interface (Barlow, 2003; McCobb and Weiskel, 2003). Barlow (2003) asserts that a rise in the groundwater level caused by sea-level rise could impact on river deltas up to $20-50 \mathrm{~km}$ inland. The magnitude of sea-level rise along the coast of the Bay of Bengal $(0.4-0.8 \mathrm{~cm} / \mathrm{yr})$ from $1977-1998$ is comparable to the trends in rising groundwater levels $(0.5-2.5 \mathrm{~cm} / \mathrm{yr})$ observed in coastal aquifers between 1985 and 2005. Rising groundwater levels may additionally result from local recharge as the volume of rainfall-fed recharge exceeds abstraction for irrigation in southern deltaic areas (BGS and DPHE, 2001). Abstraction for irrigation has declined in coastal areas of Bangladesh where rapid growth in brackish-water shrimp farming since the early 1990s has replaced many low-lying rice fields (Ahmed et al., 2009). Projected rises in sea level will accelerate the intrusion of saline water thereby impairing groundwater quality and threatening the world's largest mangrove forest in the Sundarbans (Alam, 2004) where groundwater plays a vital role in maintaining an intermediate salinity required for mangrove growth and survival (Agrawala et al., 2003). It is important to note that coastal defenses (e.g., embankments, dykes) will not inhibit (subsurface) seawater intrusion.

\subsection{Extrapolation of trends to other Asian mega-deltas}

The large number of weekly groundwater level observation data within a dense spatial network of monitoring stations in Bangladesh provides valuable information on shallow groundwater dynamics and long-term responses to rapid development and climate change in other Asian mega-deltas where geology, topography, and hydrogeological conditions of shallow aquifers are similar (Benner et al., 2008). Current groundwater abstraction in other Asian mega deltas is lower than in the GBM Delta but increasing demand for food and water in urban areas are likely to intensify groundwater abstraction. Extensive pumping from shallow aquifers in the Red River delta, particularly in Hanoi, as well as in and around Bangkok area within the Chao Phraya delta, is already causing rapid declines in groundwater levels (Phienwej et al., 2006; Berg et al., 2008). Sustainable groundwater development strategies in Asian mega-deltas need also to consider the impact of sea-level rise on costal groundwater levels.

\section{Conclusions}

We resolve recent (1985-2005) trends in groundwater levels within a highly seasonal hydrological system, the GangesBrahmaputra-Meghna (GBM) Delta, through the novel application of a robust seasonal-trend decomposition technique (STL). Seasonality dominates observed variance in groundwater levels but we show, for the first time, that groundwater levels are declining by $0.1-0.5 \mathrm{~m} / \mathrm{yr}$ in north-central, northwestern, and southwestern areas of the GBM Delta where intensive abstraction of groundwater is conducted for dryseason rice cultivation. Unsustainable groundwater abstraction is especially pronounced in areas where the low hydraulic conductivity of surface geology inhibits rainfall-fed recharge. In Dhaka where abstraction has increased dramatically to meet domestic and industrial demands, rates of groundwater-level decline exceed $1 \mathrm{~m} / \mathrm{yr}$. In the southern GBM Delta, we detect rising groundwater levels $(0.5-$ $4 \mathrm{~cm} / \mathrm{yr}$ ) that are commensurate to, and coincident with, local trends in sea levels $(0.4-0.8 \mathrm{~cm} / \mathrm{yr})$. Our analysis of the exceptional dataset of groundwater-level observations for the GBM Delta in Bangladesh provides insight into trends and seasonality in shallow groundwater levels expected in other Asian mega-deltas influenced by groundwater abstraction and global sea-level rise. Climate change will amplify observed dynamics and trends through an increase in precipitation involving fewer but more intense rainfall events during the monsoon season so future work is currently focused on the impacts of rainfall intensity on groundwater storage.

Acknowledgements. We acknowledge the support of the Bangladesh Water Development Board in providing groundwater level monitoring observation records. Support from the UK's Engineering and Physical Sciences Research Council (EPSRC) through a Dorothy Hodgkin Postgraduate Award (Ref. GR/AKFXDHPA 2007-2011) is kindly acknowledged. We thank two anonymous reviewers for their valuable comments and constructive feedback. We also thank Peter Ravenscroft, Mohammad A. Hoque, and Anwar Zahid for comments.

Edited by: A. Shamseldin

\section{References}

Aggarwal, P. K., Basu, A. R., and Poreda, R. J.: Isotope hydrology of groundwater in Bangladesh: Implications for characterisation and mitigation of arsenic in groundwater, TC Project BGD/8/016, Int. At. Energy Agency, Vienna, 2000.

Agrawala, S., Ota, T., Ahmed, A. U., Smith, J., and van Aalst, M.: Development and climate change in Bangladesh: Focus on coastal flooding and the Sundarbans, Final report, Organisation for Economic Co-operation and Development, Paris, France, 70 pp., 2003.

Ahmed, K. M., Hasan, M. K., Burgess, W. G., Dottridge, J., Ravenscroft, P., and van Wonderen, J. J.: The Dupi Tila aquifer of Dhaka, Bangladesh: hydraulic and hydrochemical response to 
intensive exploitation, in: Groundwater in the urban environment: selected city profiles, edited by: Chilton, P. J., Balkema, Rotterdam, 19-30, 1999.

Ahmed, K. M., Bhattacharya, P., Hasan, M. A., Akhter, S. H., Alam, S. M. M., Bhuyian, M. A. H., Imam, M. B., Khan, A. A., and Sracek, O.: Arsenic enrichment in groundwater of the alluvial aquifers in Bangladesh: an overview, Appl. Geochem., 19, 181200, 2004.

Ahmed, N., Allison, E. H., and Muir, J. F.: Rice fields to prawn farms: a blue revolution in southwest Bangladesh?, Aquacult. Int., doi:10.1007/s10499-009-9276-0, 2009.

Alam, M.: Subsidence of the Ganges-Brahmaputra delta of Bangladesh and associated drainage, sedimentation, and salinity problems, in: Sea-Level Rise and Coastal Subsidence: Causes, Consequences, and Strategies, edited by: Milliman, J. D. and Haq, B. U., Kluwer Academic Publishers, Dordrecht, 1996.

Alam, M.: Adverse impacts of climate change on development of Bangladesh: integrating adaptation into policies and activities, Working Paper No. 1 of CLACC, Bangladesh Centre for Advanced Studies (BCAS), Dhaka, 2004.

Aziz, O. I. A. and Burn, D. H.: Trends and variability in the hydrological regime of the Mackenzie River Basin, J. Hydrol., 319, 282-294, 2006.

BADC: Survey report on irrigation equipment and irrigated area in Boro 2003 season, Survey and monitoring project for development of minor irrigation, Bangladesh Agricultural development Corporation, Sech Bhaban, Dhaka, 2003.

Bangladesh Bureau of Statistics: Annual agricultural statistics 2007, Agricultural Wing, Bangladesh Bureau of Statistics, Dhaka, 2008.

Barlow, P. M.: Ground water in freshwater-saltwater environments of the Atlantic coast, US Geological Survey Circular 1262, US Geological Survey, Reston, Virginia, 2003.

Benner, S. G., Polizzotto, M. L., Kocar, B. D., Ganguly, S., Phan, K., Ouch, K., Sampson, M., and Fendorf, S.: Groundwater flow in an arsenic-contaminated aquifer, Mekong Delta, Cambodia, Appl. Geochem., 23, 3072-3087, 2008.

Berg, M., Trang, P. T. K., Stengel, C., Buschmann, J., Viet, P. H., Dan, N. V., Giger, W., and Stüben, D.: Hydrological and sedimentary controls leading to arsenic contamination of groundwater in the Hanoi area, Vietnam: The impact of iron-arsenic ratios, peat, river bank deposits, and excessive groundwater abstraction, Chem. Geol., 249, 91-112, 2008.

British Geological Survey and Department of Public Health Engineering (BGS and DPHE): Arsenic Contamination of Groundwater in Bangladesh, Keyworth, UK, 2001.

Chatfield, C.: The analysis of time series - an introduction, 6th Edn., Chapman and Hall, CRC Press, Boca Raton, 352 pp., 2003.

Cleveland, R. B., Cleveland, W. S., McRae, J. E., and Terpenning, I.: STL: A Seasonal Trend Decomposition Procedure Based on LOESS, J. Official Statistics, 6, 3-33, 1990.

Cleveland, W. S.: Robust Locally Regression and Smoothing Scatterplots, J. Am. Stat. Assoc., 74, 829-836, 1979.

Cleveland, W. S. and Devlin, S. J.: Locally Weighted Regression: An Approach to Regression Analysis by Local Fitting, J. Am. Stat. Assoc., 83, 596-610, 1988.

Coleman, J. M.: Brahmaputra river: channel processes and sedimentation, Sediment. Geol., 3, 1290-239, 1969.
Dawe, D.: Increasing water productivity in rice-based systems in Asia - past trends, current problems, and future prospects, Plat Prod. Sci., 8(3), 221-230, 2005.

FAO: The State of Food and Agriculture in Asia and the Pacific, RAP Publication 2006/03, Food and Agriculture Organization of the United Nations regional office for Asia and the Pacific, Bangkok, 2006.

Goodbred, S. L., Kuehl, S. A., Steckler, M. S., and Sarker, M. H.: Controls on facies distribution and stratigraphic preservation in the Ganges-Brahmaputra delta sequence, Sediment. Geol., 155, 301-316, 2003.

Hamed, K. H. and Rao, A. R.: A modified Mann-Kendall trend test for autocorrelated data, J. Hydrol., 204, 182-196, 1998.

Harvey, C. F., Ashfaque, K. N., Yu, W., Badruzzaman, A. B. M., Ali, M. A., Oates, P. M., Michael, H. A., Neumann, R. B., Beckie, R., Islam, S., and Ahmed, M. F.: Groundwater dynamics and arsenic contamination in Bangladesh, Chem. Geol., 228, 112-136, 2006.

Helsel D. R. and R. M.: Hirsch Statistical Methods in Water Resources, Book 4, Hydrologic Analysis and Interpretation, 510 pp., US Geological Survey, Virginia, 2002.

Hipel K. W. and Mcleod, A. I.: Time Series Modelling of Water Resources and Environmental System, 1013 pp., Amsterdam, Elsevier, 1994.

Hirsch, R. M. and Slack, J. R.: A nonparametric trend test for seasonal data with serial dependence, Water Resour. Res., 20, 727732, 1984.

Hirsch, R. M., Slack, J. R., and Smith, R. A.: Techniques of trend analysis for monthly water quality data, Water Resour. Res., 18, 107-121, 1982.

Hoque, M. A., Hoque, M. M., and Ahmed, K. M.: Declining groundwater level and aquifer dewatering in Dhaka metropolitan area, Bangladesh: causes and quantification, Hydrogeol. J., 15, 1523-1534, 2007.

IPCC: Climate Change 2007: the Physical Science Basis, Contribution of Working Group I to the Fourth Assessment Report of the Intergovernmental Panel on Climate Change, edited by: Solomon, S. Qin, D. Manning, M. Chen, Z. Marquis, M. Averyt, K. B. Tignor, M., and Miller, H. L., Cambridge University Press, Cambridge, UK and New York, USA, 2007.

Karim, M. A.: Upazila-wise groundwater recharge conditions of Bangladesh, Groundwater Investigation Circle, Bangladesh Water Development Board, Dhaka, 1984.

Kendall, M. G.: Rank Correlation Methods, 4th Edn., Charles Griffin, London, UK, 1975.

Klump, S., Kipfer, R., Cirpka, O. A., Harvey, C. F., Brennwald, M. S., Ashfaque, K. N., Badruzzaman, A. B. M., Hug, S. J., and Imboden, D. M.: Groundwater dynamics and arsenic mobilization in Bangladesh assessed using noble gases and tritium, Environ. Sci. Technol., 40, 243-250, 2006.

Larsen, F., Pham, N. Q., Dang, N. D., Postma, D., Jessen, S., Pham, V. H., Nguyen, T. B., Trieu, H. D., Tran, L. T., Nguyen, H., Chambon, J., Nguyen, H. V., Ha, D. H., Hue, N. T., Duc, M. T., and Refsgaard, J. C.: Controlling geological and hydrogeological processes in an arsenic contaminated aquifer on the Red River flood plain, Vietnam, Appl. Geochem., 23, 3099-3115, 2008.

Mann, H. B.: Nonparametric tests against trend, Econometrica, 13, 245-259, 1945.

McCobb, T. D. and Weiskel, P. K.: Long-Term Hydrologic Monitor- 
ing Protocol for Coastal Ecosystems, Open File Report 02-497, US Geological Survey, 94 pp., 2003.

Mohal, N., Khan, Z. H., and Rahman, N.: Impact of sea level rise on coastal rivers of Bangladesh, in Proceedings of the 10th International River Symposium and Environmental Flows Conference, Brisbane, Australia, 2007.

Mukherjee, A., Fryar, A. E., and Howell, P. D.: Regional hydrostratigraphy and groundwater flow modeling in the arsenicaffected areas of the western Bengal basin, West Bengal, India, Hydrogeol. J., 15(7), 1397-1418, doi:10.1007/s10040-0070208-7, 2007.

Norrman, J., Sparrenbom, C. J., Berg, M., Nhan D. D., Nhan, P. Q., Rosqvist H., Jacks G., Sigvardsson, E., Baric, D., Moreskog, J., Harms-Ringdahl, P., and Hoan, V. N.: Arsenic mobilisation in a new well field for drinking water production along the Red River, Nam Du, Hanoi, Appl. Geochem., 23, 3127-3142, 2008.

Phien-wej, N., Giao, P. H., and Nutalaya, P.: Land subsidence in Bangkok, Thailand, Eng. Geol., 82, 187-201, 2006.

Qian, S. S., Borsuk, M. E., and Stow, C. A.: Seasonal and longterm nutrient trend decomposition along a spatial gradient in the Neuse river watershed, Environ. Sci. Technol., 34, 4474-4482, 2000.

R Development Core Team: The R manuals, edited by: R Development Core Team, Version 2.6.0, 2007.

Ravenscroft, P., Burgess, W. G., Ahmed, K. M., Burren, M., and Perrin, J.: Arsenic in groundwater of the Bengal Basin, Bangladesh: Distribution, field relations, and hydrogeological setting, Hydrogeol. J., 13, 727-751, 2005.

Shamsudduha, M. and Uddin, A.: Quaternary shoreline shifting and hydrogeologic influence on the distribution of groundwater arsenic in aquifers of the Bengal Basin, J. Asian Earth Sci., 31, 177-194, 2007.

Siebert, S., Hoogeveen, J., and Frenken, K: Irrigation in Africa, Europe and Latin America - Update of the Digital Global Map of Irrigation Areas to Version 4, Frankfurt Hydrology Paper 05, Institute of Physical Geography, University of Frankfurt, Frankfurt am Main, Germany and Food and Agriculture Organization of the United Nations, Rome, Italy, 2006.

Singh, O. P.: Spatial variation of sea level trend along the Bangladesh coast, Mar. Geod., 25, 205-212, 2002.
Singh, O. P., Ali Khan, T. M., and Rahman, M. S.: The vulnerability assessment of the SAARC coastal region due to sea level rise: Bangladesh case, SAARC Meteorological Research Centre, Report No. 3, Dhaka, 2000.

Steckler, M., Akhter, S. H., Seeber, L., and Armbruster, J.: GPS in Bangladesh: Delta subsidence, monsoonal loading and continental collision, 2008-2012 UNAVCO Proposal, Geodesy Advancing Earth Science Research, 3-41, 2007.

Stute, M., Zheng, Y., Schlosser, P., Horneman, A., Dhar, R. K., Datta, S., Hoque, M. A., Seddique, A. A., Shamsudduha, M., Ahmed, K. M., and van Geen A.: Hydrological control of As concentrations in Bangladesh groundwater, Water Resour. Res., 43, W09417, doi:10.1029/2005WR004499, 2007.

Suwanlert, J.: Study of groundwater potential by groundwater simulation in the lower central plain of Thailand, Coordinating Committee for Geoscience Programmes in East and Southeast Asia (CCOP), 41st CCOP Annual Session, Tsukuba, Japan, 15-18, November, 2004.

Taylor, C. J. and Alley, W. M.: Groundwater level monitoring and the importance of long-term water-level data, U.S.G.S. Circular 1217, US Geological Survey, Denver, Colorado, 68 pp., 2001.

Thas, O., van Vooren, L., and Ottoy, J. P.: Selection of nonparametric methods for monotonic trend detection in water quality, J. Amer. Water Res. Assoc., 34, 347-357, 2007.

UNDP: Groundwater Survey: the Hydrogeological Conditions of Bangladesh, United Nations Development Programme (UNDP), Technical Report DP/UN/BGD-74-009/1, New York, 113 pp., 1982.

WARPO: National Water Management Plan Project, Draft Development Strategy, Main final, Vol. 2, Water Resources Planning Organization (WARPO), Dhaka, 2000.

World Bank: Towards a more effective operational response: arsenic contamination of groundwater in south and East Asian countries, Volume I \& II Technical Report, No. 31303, The World Bank, Washington, 2005.

Worm, H. U., Ahmed, A. M. M., Ahmed, N. U., Islam, H. O., Huq, M. M., Hambach, U., and Lietz J.: Large sedimentation rate in the Bengal Delta: magnetostratigraphic dating of Cenozoic sediments from northeastern Bangladesh, Geology, 26, 487-490, 1998. 